Jurnal Maenpo: Jurnal Pendidikan Jasmani kesehatan dan Rekreasi

Volume 11 Nomor 1 Tahun 2021

https://jurnal.unsur.ac.id/maenpo

This Work Is Licensed Under A Creative Commons Attribution-

Sharealike 4.0 International License @) (1) (-)

Original Article

\title{
100\% Intensity of Training on Body Weight Fluctuations Before and After Exercise
}

\section{Y. Touvan Juni Samodra}

${ }^{1}$ Pendidikan Kepelatihan olahraga, Fakultas Keguruan dan Ilmu Pendidikan, Universitas Tanjungpura, Indonesia

tovan@fkip.untan.ac.id

\begin{abstract}
ABSTRAK
Tujuan penelitian ini untuk membuktikan pengaruh intensitas latihan 100\% terhadap naik turun berat badan sebelum dan setelah latihan. Penelitian ini dilatarbelakangi adanya upaya yang dilakukan orang untuk mencapai berat badan Ideal. Salah satu upaya yang dilakukan adalah dengan melakukan latihan. Latihan yang tepat sangat diperlukan. Kualitas latihan diutunjukkan dengan intensitas latihan yang dilakukan. Penelitian menggunakan metode eksperimen. Sampel penelitian 8 mahasiswa. Dilakukan pengukuran terhadap berat badan sebelum dan setelah latihan. Perlakukan dengan menggunakan latihan sirkuit intensitas $100 \%$ berdasarkan tes maksimal. Data dianalisis dengan deskriptif statistik. Hasil penelitian menunjukkan bahwa setiap kali latihan setelah latihan selalu mengalami penurunan berat badan rerata 2,8 Ons. Berdasarkan pada hasil ini dapat dijadikan rujukan bahwa latihan sirkuit dengan beban $100 \%$ dapat dipergunakan untuk menurunkan berat badan. Rekomendasi, untuk hasil yang maksimal perlu dilakukan pencatatan asupan gizi makro, agar mengetahui diet yang layak untuk tujuan penurunan berat badan.
\end{abstract}

Kata kunci: kelebihan berat badan, obesitas, BMI, latihan sirkuit, beban maksimal.

\section{ABSTRACT}

This study aimed to prove the effect of $100 \%$ exercise intensity on weight gain before and after exercise. This research is motivated by the efforts made by people to achieve the ideal body weight. One of the efforts made is by doing exercises. Proper practice is essential. The quality of the exercise is indicated by the intensity of the exercise performed. The study used experimental methods. The research sample was eight students-measurement of body weight before and after exercise. Perform using 100\% intensity circuit training based on maximal tests. Descriptive statistics analyzed data. The results showed that they always experience an average weight loss of 2.8. Based on these results, it can reference that circuit training with $100 \%$ load could be used to lose weight. Recommendations, for maximum results, it is necessary to record macro nutritional intake, to know a proper diet for weight loss purposes.

Key words: overweight, obesity, BMI, circuit training, maximul load 
Received: 02-06-2021; Accepted: 16-06-2021; Published: 20-06-2021

2021 Universitas Suryakancana

e-ISSN: 2721-7175(online) p-ISSN: 2089-2341 (cetak)

\section{PENDAHULUAN}

Salah satu ukuran dalam mempertahankan kesehatan adalah berat badan ideal. Orang mengidamkan berat badan yang ideal dan menghindari terjadinya kelebihan berat badan. Review penelitian memberikan pencerahan bahwa kelebihan berat badan akan menjadikan masalah pada kehidupan. (Akinpelu, Oyewole, \& Adekanla, 2015) memberikan keterangan bahwa penduduk di Negeria tidak menganggap berat badan adalah sesuatu yang penting, padahal kenyataan menunjukkan 55\% mengalami ovesitas berdasarkan perhitungan BMI. Sebuah penelitian memberikan data menarik dengan menganalisa anak yang mengalami obesitas dari tahun 1980-2015 memberikan gambaran bahwa ternyata terjadi peningkatan jumlah anak yang mengalami obesitas antara anak anak dan orang dewasa lebih besar terjadi pada anak anak (Afshin et al., 2017). Penelitian ini memberikan perhatian khusus pada upaya pencegahan naiknya BMI anak anak, jika hal ini dibiarkan maka akan terjadi ledakan penderita obesitas. Percepatan kenaikan berat badan dengan meningkatnya BMI pada masa pertumbuhan anak usia 2 dan 6 tahun diprediksikan akan mengalami obesitas di usia dewasa (Geserick et al., 2018). Hasil penelitian ini merupakan fakta yang menarik dan perlu untuk mendapat perhatian. Anak yang sehat bukan dilihat dari gemuknya, gemuk di usia anak akan berakibat pada jangka panjang.

Obesitas ditunjukkan dengan ukuran BMI, obesitas ini menjadi permasalah kesehatan yang berdampak pada kematian dan telah menyedot jutaan dolar anggaran (Markowitz, 2018). Beberapa hal yang menjadikan obesitas dan kelebihan berat badan subur adalah termasuk faktor keturunan, faktor lingkungan dan perilaku hidup (Daniels \& Bolling, 2016). Kalainan pola makan northorexia nervosa terjadi, hal ini berkaitan dengan semakin meningkatnya BMI personality (Oberle, Samaghabadi, \& Hughes, 2017). Obesitas level 1 (BMI 30.0-<35.0 kg/m 2 ), level $2(35 \cdot 0-<40 \cdot 0$ $\mathrm{kg} / \mathrm{m} 2$ ), level $3(40 \cdot 0-<60 \cdot 0 \mathrm{~kg} / \mathrm{m} 2$ ) (Di Angelantonio et al., 2016). Berdasarkan 
pada pendapat ini, sangat mudah untuk mengetahui status seseorang yang mengalami kelebihan berat badan ataupun sudah sampai level obesitas.

Terdapat korelasi antara prosentase lemak dengan terhadap kelincahan dengan angka korelasi 0.55 , sedangkan antara prosentase lemak, berat badan dan kelincahan berkorelasi 0.606 (Widiastuti W, Hendro Wardoyo, Hernawan H, 2020). Prosentase lemak ini akan berkaitan dengan obesitas jika terlalu tinggi. Pengaruh kelebihan berat badan ini memberikan dampak yang sangat luar biasa bagi kehidupan seseorang. Obesitas berasosiasi dengan kematian pasien kanker (Taghizadeh et al., 2015). Kenaikan berat badan akan terjadi jika mantan atlet tidak memelihara kebugaran dan tidak hidup aktif. Penelitian yang dilakukan oleh (Mela Aryani, 2018), memberikan data bahwa tingkat kebugaran jasmani hanya 7\% yang memiliki level kebugaran baik dan selebihnya sedang dan kurang, hal ini bukan sesuatu yang menggembirakan. Selanjutnya data sebuah penelitian yang sangat memperihatinkan menyebutkan beberapa hal kaitan dengan pengaruh olahragawan elit (dari yang pensiun dari kegiatan olahraga dan hanya hidup sebagai orang normal, menunjukkan 4 terkena arrhythmias, 3 kanker mulut, dada, dan melanoma, 1 asma, 1 diabetes. Hanya 12 (60\%) tidak terjebak minuman keras, 5 orang peminum, lebih dari 2 orang dalam pengobatan karena bypass jantung. BMI 24.8. 9 orang dilaporkan kelebihan berat badan dan setengah dari mereka BM normal tetapi perokok, 3 darah tinggi, mengalami depresi 6 (30\%) dan hanya 2 (10\%) yang normal dari depresi (L., V.D.T., \& M.Y., 2015), Penelitian ini dilakukan setelah atlet-atlet tersebut berhenti latihan rerata selama 20 tahun.

Latihan dengan media sepak bola dengan intensitas moderat selama 12 minggu terhadap anak yang mengalami obesitas, ternyata berpengaruh postif terhadap perubahan kebugaran, dan beberapa indikator perubahan dari pengukuran terhadap antopometri (Reale, Burke, Cox, \& Slater, 2020). Telah dilakukan banyak penelitian untuk mengatasi obesitas ini. Beberapa diantaranya adalah latihan 14 sesi dengan dosis lari intensitas rendah volume tinggi (8x 20 s, 10 s rest; set rest: 5 min) dapat meningkatan Vo2max dan daya tahan otot (Menz et al., 2019). Dilakukan penelitian terhadap orang yang menderita diabet tipe 2 ternyata latihan HIIT lebih cocok 
dilakukan di sore hari, di sore hari akan terjadi adaptasi yang positif sedangkan di pagi hari akan terjadi kerusakan yang akut dan terjadi peningkatan glukosa darah (Savikj et al., 2019).

Latihan HIIT lebih baik hasilnya terhadap penurunan systole tekanan darah dibandingkan dengan latihan moderat, sementara itu baik HIIT ataupun latihan moderat memiliki pengaruh yang sama terhadap hasil kelenturan pembuluh darah arteri (Way, Sultana, Sabag, Baker, \& Johnson, 2019). HIIT menurunkan massa lemak, persentase lemak di perut dan memperbaiki BMI (Dun, Smith, Liu, \& Olson, 2019). Menurunkan berat badan, memperbaiki BMI, menurunkan persentase lemak dan kolesterol serta memperbaiki $\mathrm{VO}_{2} \max$ (Su et al., 2019). Latihan dengan 3 kali seminggu selama 8-12 minggu menggunakan interval 30 detik latihan 30 detik istirahat, hasil penelitian terjadi peningkatan signifikan pada masa otot, kemampuan melakukan ulangan, kebugaran kardio respirasi, tetapi tidak signifikan terhadap kompsisi tubuh, standing long jump, kecemasan (Eather et al., 2019)

Latihan HIIT terhadap orang dewasa yang mengalamai kelebihan berat badan dan obesitas dapat meningkatkan sensitifitas insulin, memperbaiki tekanan darah dan kompoisi tubuh, hal ini sama dengan latihan intensitas moderat yang dilakukan secara berkelanjutan (Campbell et al., 2019). Penelitian dengan observasi selama 1 tahun terhadap penderita diabet tipe 2, ternyata latihan dengan intetensitas tinggi adalah hanya yang paling berpengaruh untuk memperbaiki komplikasi pembuluh darah (Cao, Quan, \& Zhuang, 2019). Temuan penelitian mengungkapkan bahwa latihan dengan intensitas tinggi terhadap pasisen yang sedang mejalani kemoterapi dapat meningkatkan kesehatan (Mijwel et al., 2019), terhadap kapasitas aerobic kepada penderita diabet tipe 2 (Hwang et al., 2019)

Terdapat pengaruh yang sama antara HIIT dan intensitas moderat terhadap perubahan kualitas hidup dengan indikator massa otot dan penurunan lemak tubuh (Mugele et al., 2019). Latihan dengan intensitas tinggi ternyata hasilnya sama dengan intensitas moderat kontinus terhadap pengukuran antopometri tubuh (Andreato, Esteves, Coimbra, Moraes, \& de Carvalho, 2019). Latihaan intensitas tinggi menunjukkan adanya peningkatan $\mathrm{VO}_{2} \mathrm{max}$, hasil tes intermiten dan kecapatan 
aerobic (Delgado-Floody, Latorre-Román, Jerez-Mayorga, Caamaño-Navarrete, \& García-Pinillos, 2019) juga berpegaruh terhadap kecepatan, kekutan dan kualitas hidup orang tua (usia 82 tahun) (Jiménez-García et al., 2019). Latihan selama 3 minggu ternyata dapat meningkatan $\mathrm{VO}_{2}$ peak lebih efektif dibandingkan dengan latihan dengan intensitas rendah dan moderat (Williams et al., 2019), mempertahankan $\mathrm{VO}_{2} \max$ (Lee et al., 2019); (Ito, 2019). Latihan interval kurang dari 30 meter dengan volume rendah (kurang dari 5 menit) selama 4 minggu ternyata efektif untuk mengembangkan $\mathrm{VO}_{2}$ max, namum demikian lebih dianjurkan latihan dengan dosis interval panjang (lebih dari 2 menit) dengan volume tinggi (lebih dari 15 menit) selama 4-12 minggu dengan HIIT (Wen et al., 2019)

Berdasarkan pada penelitian penelitian di atas, latihan intensitas tinggi memiliki daya yang ampuh untuk mengatasi berbagai permasalahan menaikkan dan mempertahankan $\mathrm{VO}_{2} \max$ (Su et al., 2019); (Wen et al., 2019); (Williams et al., 2019); (Lee et al., 2019); (Ito, 2019), memperbaiki antopometri (Andreato et al., 2019); (Su et al., 2019); (Menz et al., 2019); menangani berat badan (Mugele et al., 2019); (Su et al., 2019). Penelitian ini menggunakan latihan sirkuit dengan intensitas $100 \%$. Fokus dalam penelitian ini adalah untuk melihat penurunan berat badan ketika latihan dan mendapatkan beban 100\% dengan metode sirkuit. Diketahui bahwa setiap artikel selalu menggunakan desain pre tes dan post tes, dalam penelitian ini diungkapkan data berat badan sebelum dan setelah latihan.

Penelitian ini membuktikan bahwa latihan yang dilakukan pasti memberikan pengaruh. Pengaruh yang dimaksudkan adalah adanya perubahan terhadap penurunan berat badan. Pertanyaan masyarakat yang kurang percaya dengan keefektifan latihan dapat terjawab dari sudut pandang intensitas latihan. Bukti yang diberikan sangat nyata dengan pengukuran yang dilakukan sebelum dan setelah melakukan latihan dengan intensitas tinggi (100\%).

\section{METODE}

Penelitian dilakukan dengan desain eksperimen. Dilakukan pengukuran terhadap berat badan sebelum dan setelah latihan. Perlakuan yang diberikan adalah 
dengan memberikan latihan sirkuit latihan beban. Latihan dilakukan tiga kali dalam seminggu selama 12 kali pertemuan setiap selang sehari, dilakukan pada hari Senin, Rabu dan Jum'at mulai jam 18.15 sampai jam 19.15. Berat badan diukur dengan timbangan digital merk Tanaka. Analisis data menggunakan statistik deskriptif.

\section{HASIL DAN PEMBAHASAN}

\section{Hasil Penelitian}

Penelitian ini dilakukan selama 12 kali pertemuan. Pelaksanaan pertemuan penelitian dilakukan selama 12 kali ternyata hanya 2 orang yang secara utuh mampu melaksanakan latihan sampai 12 kali, 1 orang 11 kali, 1 orang 9 kali, 3 orang 8 kali dan 1 orang 7 kali. Hasil penelitian kemudian di deskripsikan dalam bentuk tabel sebagai berikut:

Tabel 1. Hasil Perhitungan Rerata penurunan berat badan 8 Sampel Penelitian.

\begin{tabular}{|c|c|c|c|c|c|}
\hline Sampel & $\begin{array}{l}\text { Jumlah } \\
\text { latihan }\end{array}$ & Mean & Std. & Min & Max \\
\hline A & 9 & .4256 & .17501 & .15 & .68 \\
\hline B & 8 & .2375 & .09161 & .15 & .40 \\
\hline $\mathrm{C}$ & 12 & .2208 & .08649 & .10 & .40 \\
\hline D & 7 & .3643 & .06901 & .25 & .45 \\
\hline $\mathrm{E}$ & 8 & .3725 & .05849 & .30 & .47 \\
\hline $\mathrm{F}$ & 12 & .2708 & .06557 & .15 & .40 \\
\hline G & 11 & 2909 & .12413 & .10 & .45 \\
\hline $\mathrm{H}$ & 8 & .1625 & .03536 & .10 & .20 \\
\hline Total & 75 & .2888 & .12308 & .10 & .68 \\
\hline
\end{tabular}

Berdasarkan tabel 1 di atas, dapat diterangkan bahwa nilai minimal penurunan berat badan adalah 1 ons. Maksimal terjadi sampai hampir 7 ons (di 6.8 0ns). Data fluktuasi ini memberikan bukti bahwa dengan 12 alat, 3 set latihan melakukan latihan pasti terjadi penurunan berat badan. Secara garis besar dapat diperhatikan pada tabel 1, bahwa rerata dari semua kejadian (75 kejadian) pengukuran yang dilakukan dipastikan terjadi penurunan berat badan 0.288 ons sekali latihan. Lebih lanjut data 
ini disajikan dalam bentuk tabel. Tabel 1 berikut adalah tampilan data dari ke 8 sampel yang melakukan latihan.

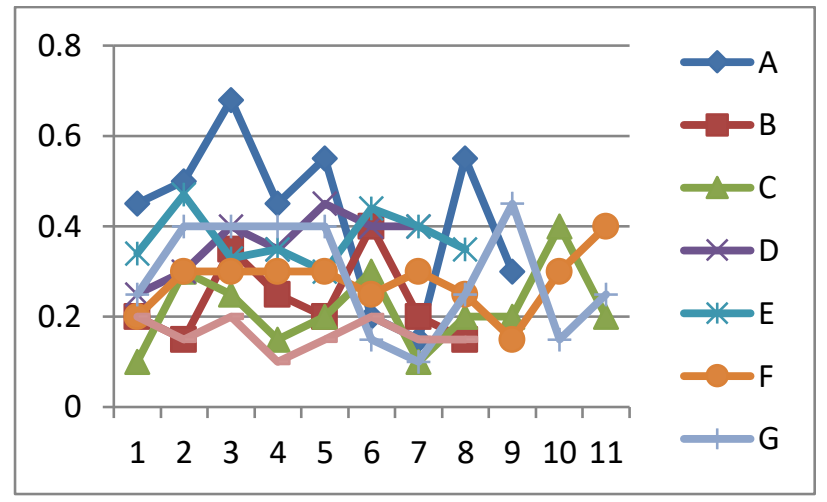

Gambar 1. Grafik Fluktuasi Berat Badan Latihan 100\%

Berdasarkan pada gambar 1 di atas dapat dilihat bahwa, tidak satupun dari sampel penelitian yang berat badannya tetap atau naik setelah latihan. Seratus persen sampel penelitian mengalami penurunan berat badan dengan melakukan latihan dosis $100 \%$.

\section{Pembahasan}

Latihan intensitas tinggi terhadap kebugaran

Latihan dengan intensitas tinggi tidaklah mudah dan menyenangkan. Seperti halnya dalam penelitian ini dari awalnya 12 sampel, tidak semua orang coba secara konsisten selalu hadir dalam penelitian, setidaknya terdapat 4 sampel tidak dapat dimasukkan dalam analisis, karena orang coba akhirnya tidak pernah masuk. Hal ini sama halnya yang terjadi pada penelitian berikut, penelitian membandingkan kondisi yang menyebabkan orang mengundurkan diri dari latihan dari berbagai intensitas, HIIT, moderat dan kontinu, hasil penelitian ternyata kelompok intensitas tinggi dan moderat lebih sedikit terjadinya mortality (Stensvold et al., 2020).

Terjadi adaptasi yang positif latihan dengan HIIT shock microcycle, hal ini dilihat dari adaptasi mitokondria (Dolci, Kilding, Chivers, Piggott, \& Hart, 2020). Dalam isitilah lain HIIT shock microcyle ini disebut sebagai latihan system block. Membandingkan latihan interval intensitas tinggi dengan sprint intensitas tinggi terhadap waktu time trial (TT) ternyata antara HIIT dan SI hasilnya tidak jauh berbeda, tetapi secara lebih mendalam terdapat HIIT lebih besar terjadi peningkatan 
sampai 2\% (Rosenblat, Perrotta, \& Thomas, 2020). Bahkan dilakukan penelitian terhadap orang yang mengalami gangguan mental, HIIT dengan memperhatikan standar keamanan ternyata latihan HIIT ini lebih meningkatkan depresi dibandingkan dengan latihan moderat, tetapi secara fisiologi HITT dan moderat sama pengaruhnya terhadap kebugaran kardiorespirasi (Korman et al., 2020).

Latihan intensitas tinggi efektif untuk meningkatkan kebugaran kardio respirasi, dan direkomendasikan untuk program pendidikan jasmani (Martin-Smith et al., 2020). Latihan memberikan pengaruh terhadap keterlibatan dalam bermain, kemampuan menjelajah jarak dan meningkatkan jumlah sprint yang dilakukan (Kunz, Engel, Holmberg, \& Sperlich, 2019). Penelitian meta analisa terhadap 33 penelitian, memberikan bukti bahwa HIIT meningkatkan kebugaran kardio, antrophometri, kontrol glokosa dan glikemik, pengontrolan fungsi pembuluh darah dan pembuluh darah jantung, denyut nadi, pengontrolan terhadap inflamasi, peningkatan kapasitas latihan dan masa otot, semua review penelitian ini atas dasar penelitian yang dibandingkan dengan kelompok kontrol (Martland, Mondelli, Gaughran, \& Stubbs, 2020).

Penelitian yang dilakukan terhadap anak anak dan remaja membuktikan bahwa latihan intensitas tinggi pengaruhnya lebih besar dibandingkan Moderat, penelitian dilakukan terhadap peningkatan kebugaran kardiorespirasi (Cao et al., 2019). Latihan selama 6 bulan dengan 3 kali seminggu memberikan hasil bahwa latihan dengan intensitas tinggi lebih baik pengaruhnya terhadap oksigen uptake, kualitas hidup, toleransi terhadap kelelahan (Tew et al., 2019). Latihan interval intensitas tiggi dalam waktu yang lama terjadi peningkatan $\mathrm{VO}_{2} \max$, lebih baik dibandingkan dengan intensitas moderat (Naves et al., 2019)

Latihan intensitas tinggi terhadap orang sakit

Direkomendasikan untuk latihan latihan intensitas tinggi dikontrol dengan pengukuran yang subyektif dan juga obyektif mengenai intensitas latihan kedua, diperlukan kontrol secara klinis untuk memonitor penilaitan dan memaksimalkan dari sisi keamanan (Taylor et al., 2019). Latihan HIIT ternyata memilili pengaruh jangka panjang terhadap kesehatan pasien kemo terapi kanker payudara (Bolam, Mijwel, 
Rundqvist, \& Wengström, 2019). Penelitian dengan sampel kecil memberikan hasil bahwa latihan dengan intensitas tinggi meningkatkan fungsi kognisi dan meningkatkan kemampuan fungsi otot otak, kebugaran pada penderita kanker payudara (Northey et al., 2019).

Sebuah penelitian memberikan rekomendasi bahwa penggunaan intensitas tinggi untuk kepentingan rehabilitasi kesehatan bagi penderita jantung coroner, hal ini harus sangat diawasi dan perlu evaluasi yang hati hati (Quindry, Franklin, Chapman, Humphrey, \& Mathis, 2019). Saran ini terutama dengan semakin banyaknya penelitian dengan intensitas yang tinggi untuk mengatasi berbagai permasalahan serta untuk meningkatkan kualitas kesehatan dan juga termasuk di dunia terapi.

Latihan intensitas tinggi terhadap kelebihan berat badan

Dalam latihan beta-alanine (asam anino esensial) sangat berpengaruh terhadap peningkatan intensitas latihan dan dapat meningkatkan adaptasi (Forbes et al., 2020). Latihan dengan dosis $90 \%$ nadi, hasilnya terjadi peningkatan kapasitas aerobic, terjadi penurunan massa lemak setelah 4 minggu latihan tubuh, sistol tekanan darah setelah latihan 8 minggu (Chin et al., 2020) (Chin et al., 2020) merekomendasikan untuk program intensitas tinggi diperbanyakkan untuk mengatasi orang yang kelebihan berat badan dan obesitas. Pengaruh volume rendah dengan intensitas tingi ternyata tidak efektif untuk menurunkan lemak, persentasi lemak dan komposisi tubuh (Sultana, Sabag, Keating, \& Johnson, 2019), sehingga bedasarkan pada temuan penelitian ini maka untuk latihan yang lebih disarankan ketika menggunakan intensitas dan juga menggunakan volume tinggi.

Berdasarkan temuan dalam penelitian ini diperoleh hasil bahwa setiap sebelum dan setelah latihan, jika dilakukan pengukuran berat badan, orang coba mengalami penurunan berat badan dengan rerata penurunan 2,8 ons. Penurunan ini kemudian diamati data selama proses penelitian terjanyata hampir semua orang coba setiap kali datang latihan, hasil penimbangan tidak jauh berbeda. Hal ini memberikan indikasi bahwa semua orang coba telah melakukan asupan gizi makro yang cukup, sehingga berat badan akan kembali pada pulih asal. Penelitian ini mempertegas 
bahwa dengan latihan sirkuit dosis $100 \%$ pasti akan menurunkan berat badan sebelum dan setelah latihan.

Kelemahan penelitian, kelanjutan dari penelitian ini untuk dicermati adalah perlu adanya pencatatan nutrisi yang masuk serta aktivitas apa yang dilakukan untuk melihat kecermatan berat badan kembali pada pulih asal setiap datang latihan. Sangat terbukti bahwa setelah latihan akan terjadi penurunan berat badan, selanjutnya perlu adanya kontrol terhadap asupun gizi jika dosis ini dipergunakan untuk melakukan penurunan berat badan. Penelitian selanjutnya disarankan untuk melihat variabel pemenuhan gizi selama latihan menjadi sebagai variabel yang diamati.

\section{SIMPULAN.}

Hasil penelitian menggambarkan bahwa dengan beban $100 \%$ dengan metode sirkuit selalu terjadi penurunan berat badan. Penurunan yang terjadi rerata 2,8 ons. Penurunan ini bukan merupakan penurunan permanen. Asupan nutrisi makro (karbohidrat, lemak dan protein) tidak disertakan dalam pengendalian penelitian, sehingga terjadi pulih asal untuk berat badan

\section{DAFTAR PUSTAKA}

Afshin, A., Forouzanfar, M. H., Reitsma, M. B., Sur, P., Estep, K., Lee, A., ... Murray, C. J. L. (2017). Health effects of overweight and obesity in 195 countries over 25 years. New England Journal of Medicine, Med 2017;, 13-27. https://doi.org/10.1056/NEJMoa1614362

Akinpelu, A., Oyewole, O., \& Adekanla, B. (2015). Using the BMI-for-age Growth Charts. Annals of Medical and Health Sciences Research. https://doi.org/10.4103/2141-9248.165247

Andreato, L. V., Esteves, J. V., Coimbra, D. R., Moraes, A. J. P., \& de Carvalho, T. (2019). The influence of high-intensity interval training on anthropometric variables of adults with overweight or obesity: a systematic review and network meta-analysis. Obesity Reviews, 20(1), 142-155. https://doi.org/10.1111/obr.12766

Bolam, K. A., Mijwel, S., Rundqvist, H., \& Wengström, Y. (2019). Two-year followup of the OptiTrain randomised controlled exercise trial. Breast Cancer Research and Treatment, 175(3), 637-648. https://doi.org/10.1007/s10549-01905204-0

Campbell, W. W., Kraus, W. E., Powell, K. E., Haskell, W. L., Janz, K. F., Jakicic, J. M., ... Bartlett, D. B. (2019). High-Intensity Interval Training for 
Cardiometabolic Disease Prevention. Medicine and Science in Sports and Exercise, 51(6), 1220-1226. https://doi.org/10.1249/MSS.0000000000001934

Cao, M., Quan, M., \& Zhuang, J. (2019). Effect of high-intensity interval training versus moderate-intensity continuous training on cardiorespiratory fitness in children and adolescents: A meta-analysis. International Journal of Environmental Research and Public Health, 16(9), 1533. https://doi.org/10.3390/ijerph16091533

Chin, E. C., Yu, A. P., Lai, C. W., Fong, D. Y., Chan, D. K., Wong, S. H., ... Siu, P. M. (2020). Low-frequency HIIT improves body composition and aerobic capacity in overweight men. Medicine and Science in Sports and Exercise, 52(1), 56-66. https://doi.org/10.1249/MSS.0000000000002097

Daniels, S. R., \& Bolling, C. F. (2016). Obesity. In The Curated Reference Collection in Neuroscience and Biobehavioral Psychology. https://doi.org/10.1016/B978-012-809324-5.23631-6

Delgado-Floody, P., Latorre-Román, P., Jerez-Mayorga, D., Caamaño-Navarrete, F., \& García-Pinillos, F. (2019). Feasibility of incorporating high-intensity interval training into physical education programs to improve body composition and cardiorespiratory capacity of overweight and obese children: A systematic review. Journal of Exercise Science and Fitness, 17(2), 35-40. https://doi.org/10.1016/j.jesf.2018.11.003

Di Angelantonio, E., Bhupathiraju, S. N., Wormser, D., Gao, P., Kaptoge, S., de Gonzalez, A. B., ... Hu, F. B. (2016). Body-mass index and all-cause mortality: individual-participant-data meta-analysis of 239 prospective studies in four continents. The Lancet, 20(388), 776-786. https://doi.org/10.1016/S01406736(16)30175-1

Dolci, F., Kilding, A. E., Chivers, P., Piggott, B., \& Hart, N. H. (2020). HighIntensity Interval Training Shock Microcycle for Enhancing Sport Performance: A Brief Review. Journal of Strength and Conditioning Research, 34(3), 11881196. https://doi.org/10.1519/JSC.0000000000003499

Dun, Y., Smith, J. R., Liu, S., \& Olson, T. P. (2019). High-Intensity Interval Training in Cardiac Rehabilitation. Clinics in Geriatric Medicine, 42(7), 587-605. https://doi.org/10.1016/j.cger.2019.07.011

Eather, N., Riley, N., Miller, A., Smith, V., Poole, A., Vincze, L., ... Lubans, D. R. (2019). Efficacy and feasibility of HIIT training for university students: The Uni-HIIT RCT. Journal of Science and Medicine in Sport, 22(5), 596-601. https://doi.org/10.1016/j.jsams.2018.11.016

Forbes, S. C., Candow, D. G., Smith-ryan, A. E., Hirsch, K. R., Roberts, M. D., Vandusseldorp, T. A., ... Little, J. P. (2020). Supplements and nutritional interventions to augment high-intensity interval training physiological and performance adaptations - A narrative review. Nutrients, 12(2), 390. https://doi.org/10.3390/nu12020390

Geserick, M., Vogel, M., Gausche, R., Lipek, T., Spielau, U., Keller, E., ... Körner, A. (2018). Acceleration of BMI in early childhood and risk of sustained obesity. New England Journal of Medicine, 379, 1303-1312. https://doi.org/10.1056/NEJMoa1803527 
Hwang, C. L., Lim, J., Yoo, J. K., Kim, H. K., Hwang, M. H., Handberg, E. M., ... Christou, D. D. (2019). Effect of all-extremity high-intensity interval training vs. moderate-intensity continuous training on aerobic fitness in middle-aged and older adults with type 2 diabetes: A randomized controlled trial. Experimental Gerontology, 116, 46-53. https://doi.org/10.1016/j.exger.2018.12.013

Ito, S. (2019). High-intensity interval training for health benefits and care of cardiac diseases - The key to an efficient exercise protocol. World Journal of Cardiology, 11(7), 171-188. https://doi.org/10.4330/wjc.v11.i7.171

Jiménez-García, J. D., Martínez-Amat, A., De La Torre-Cruz, M. J., FábregaCuadros, R., Cruz-Díaz, D., Aibar-Almazán, A., ... Hita-Contreras, F. (2019). Suspension Training HIIT Improves Gait Speed, Strength and Quality of Life in Older Adults. International Journal of Sports Medicine, 40(2), 116-124. https://doi.org/10.1055/a-0787-1548

Korman, N., Armour, M., Chapman, J., Rosenbaum, S., Kisely, S., Suetani, S., ... Siskind, D. (2020). High Intensity Interval training (HIIT) for people with severe mental illness: A systematic review \& meta-analysis of intervention studiesconsidering diverse approaches for mental and physical recovery. Psychiatry Research, 284, 112601. https://doi.org/10.1016/j.psychres.2019.112601

Kunz, P., Engel, F. A., Holmberg, H. C., \& Sperlich, B. (2019). A Meta-Comparison of the Effects of High-Intensity Interval Training to Those of Small-Sided Games and Other Training Protocols on Parameters Related to the Physiology and Performance of Youth Soccer Players. Sports Medicine - Open, 5(1), 7. https://doi.org/10.1186/s40798-019-0180-5

L., S., V.D.T., D. T., \& M.Y., M. (2015). Metabolic and pshycological aspects as consequences of sports interruption in ex-elite athletes. European Journal of Preventive Cardiology.

Lee, K., Kang, I., Mack, W. J., Mortimer, J., Sattler, F., Salem, G., \& DieliConwright, C. M. (2019). Feasibility of high intensity interval training in patients with breast Cancer undergoing anthracycline chemotherapy: A randomized pilot trial. BMC Cancer, 19(1), 653. https://doi.org/10.1186/s12885019-5887-7

Markowitz, J. S. (2018). Body mass index (BMI). In SpringerBriefs in Public Health. https://doi.org/10.1007/978-3-319-77203-5_5

Martin-Smith, R., Cox, A., Buchan, D. S., Baker, J. S., Grace, F., \& Sculthorpe, N. (2020). High intensity interval training (HIIT) improves cardiorespiratory fitness (CRF) in healthy, overweight and obese adolescents: A systematic review and meta-analysis of controlled studies. International Journal of Environmental

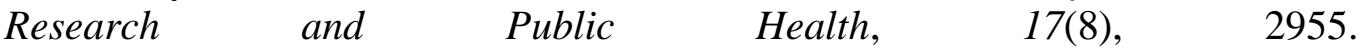
https://doi.org/10.3390/ijerph17082955

Martland, R., Mondelli, V., Gaughran, F., \& Stubbs, B. (2020). Can high-intensity interval training improve physical and mental health outcomes? A meta-review of 33 systematic reviews across the lifespan. Journal of Sports Sciences, 38(1), 1-40. https://doi.org/10.1080/02640414.2019.1706829

Mela Aryani. (2018). Profil Tingkat Kebugaran Jasmani Mahasiswa Pjkr Universitas Suryakancana Mela Aryani. Jurnal Maenpo, 8(1), 81-88. 
https://doi.org/https://doi.org/10.35194/jm.v8i1.919

Menz, V., Marterer, N., Amin, S. B., Faulhaber, M., Hansen, A. B., \& Lawley, J. S. (2019). Functional vs. Running low-volume high-intensity interval training: Effects on vo2max and muscular endurance. Journal of Sports Science and Medicine, 18(3), 497-504.

Mijwel, S., Jervaeus, A., Bolam, K. A., Norrbom, J., Bergh, J., Rundqvist, H., \& Wengström, Y. (2019). High-intensity exercise during chemotherapy induces beneficial effects 12 months into breast cancer survivorship. Journal of Cancer Survivorship, 13(2), 244-256. https://doi.org/10.1007/s11764-019-00747-z

Mugele, H., Freitag, N., Wilhelmi, J., Yang, Y., Cheng, S., Bloch, W., \& Schumann, M. (2019). High-intensity interval training in the therapy and aftercare of cancer patients: a systematic review with meta-analysis. Journal of Cancer Survivorship, 13(2), 205-223. https://doi.org/10.1007/s11764-019-00743-3

Naves, J. P. A., Rebelo, A. C. S., Silva, L. R. B. E., Silva, M. S., Ramirez-Campillo, R., Ramírez-Vélez, R., \& Gentil, P. (2019). Cardiorespiratory and perceptual responses of two interval training and a continuous training protocol in healthy young men. European Journal of Sport Science, 19(5), 653-660. https://doi.org/10.1080/17461391.2018.1548650

Northey, J. M., Pumpa, K. L., Quinlan, C., Ikin, A., Toohey, K., Smee, D. J., \& Rattray, B. (2019). Cognition in breast cancer survivors: A pilot study of interval and continuous exercise. Journal of Science and Medicine in Sport, 22(5), 580585. https://doi.org/10.1016/j.jsams.2018.11.026

Oberle, C. D., Samaghabadi, R. O., \& Hughes, E. M. (2017). Orthorexia nervosa: Assessment and correlates with gender, BMI, and personality. Appetite, Appetite., 303-310. https://doi.org/10.1016/j.appet.2016.10.021

Quindry, J. C., Franklin, B. A., Chapman, M., Humphrey, R., \& Mathis, S. (2019). Benefits and Risks of High-Intensity Interval Training in Patients With Coronary Artery Disease. American Journal of Cardiology, 123(8), 1370-1377. https://doi.org/10.1016/j.amjcard.2019.01.008

Reale, R., Burke, L. M., Cox, G. R., \& Slater, G. (2020). Body composition of elite Olympic combat sport athletes. European Journal of Sport Science, 20(15), 134. https://doi.org/10.1080/17461391.2019.1616826

Rosenblat, M. A., Perrotta, A. S., \& Thomas, S. G. (2020). Effect of High-Intensity Interval Training Versus Sprint Interval Training on Time-Trial Performance: A Systematic Review and Meta-analysis. Sports Medicine, 50(6), 1145-1161. https://doi.org/10.1007/s40279-020-01264-1

Savikj, M., Gabriel, B. M., Alm, P. S., Smith, J., Caidahl, K., Björnholm, M., ... Wallberg-Henriksson, H. (2019). Afternoon exercise is more efficacious than morning exercise at improving blood glucose levels in individuals with type 2 diabetes: a randomised crossover trial. Diabetologia, 62(2), 233-237. https://doi.org/10.1007/s00125-018-4767-z

Stensvold, D., Viken, H., Steinshamn, S. L., Dalen, H., Støylen, A., Loennechen, J. P., ... Wisløff, U. (2020). Effect of exercise training for five years on all cause mortality in older adults-The Generation 100 study: Randomised controlled trial. The BMJ, 371, m3485. https://doi.org/10.1136/bmj.m3485 
Su, L. Q., Fu, J. M., Sun, S. L., Zhao, G. G., Cheng, W., Dou, C. C., \& Quan, M. H. (2019). Effects of HIIT and MICT on cardiovascular risk factors in adults with overweight and/or obesity: A meta-analysis. PLoS ONE, 14(2), e0210644. https://doi.org/10.1371/journal.pone.0210644

Sultana, R. N., Sabag, A., Keating, S. E., \& Johnson, N. A. (2019). The Effect of Low-Volume High-Intensity Interval Training on Body Composition and Cardiorespiratory Fitness: A Systematic Review and Meta-Analysis. Sports Medicine, 49(11), 1687-1721. https://doi.org/10.1007/s40279-019-01167-w

Taghizadeh, N., Boezen, H. M., Schouten, J. P., Schröder, C. P., De Vries, E. G. E., \& Vonk, J. M. (2015). BMI and lifetime changes in BMI and cancer mortality risk. PLoS ONE, 10(4), e0125261. https://doi.org/10.1371/journal.pone.0125261

Taylor, J. L., Holland, D. J., Spathis, J. G., Beetham, K. S., Wisløff, U., Keating, S. E., \& Coombes, J. S. (2019). Guidelines for the delivery and monitoring of high intensity interval training in clinical populations. Progress in Cardiovascular Diseases, 62(2), 140-146. https://doi.org/10.1016/j.pcad.2019.01.004

Tew, G. A., Leighton, D., Carpenter, R., Anderson, S., Langmead, L., Ramage, J., ... Bottoms, L. (2019). High-intensity interval training and moderate-intensity continuous training in adults with Crohn's disease: A pilot randomised $\begin{array}{llll}\text { controlled trial. } \quad B M C & \text { Gastroenterology, }\end{array}$ https://doi.org/10.1186/s12876-019-0936-x

Way, K. L., Sultana, R. N., Sabag, A., Baker, M. K., \& Johnson, N. A. (2019). The effect of high Intensity interval training versus moderate intensity continuous training on arterial stiffness and $24 \mathrm{~h}$ blood pressure responses: A systematic review and meta-analysis. Journal of Science and Medicine in Sport. https://doi.org/10.1016/j.jsams.2018.09.228

Wen, D., Utesch, T., Wu, J., Robertson, S., Liu, J., Hu, G., \& Chen, H. (2019). Effects of different protocols of high intensity interval training for VO2max improvements in adults: A meta-analysis of randomised controlled trials. Journal of Science and Medicine in Sport, 22(8), 941-947. https://doi.org/10.1016/j.jsams.2019.01.013

Widiastuti W, Hendro Wardoyo, Hernawan H, S. N. (2020). Hubungan Prosentase Lemak dan Berat Badan Dengan Agility Klub Pencak Silat Nusantara DKI Jakarta Usia 11-18 Tahun. Jurnal Maenpo, 10(2), 57-63. https://doi.org/https://doi.org/10.35194/jm.v10i2.943

Williams, C. J., Gurd, B. J., Bonafiglia, J. T., Voisin, S., Li, Z., Harvey, N., ... Coombes, J. S. (2019). A multi-center comparison of VO2peak trainability between interval training and moderate intensity continuous training. Frontiers in Physiology. https://doi.org/10.3389/fphys.2019.00019 